\title{
Presentación. \\ Seminario internacional sobre milenarismo, mesianismo, pensamiento utópico y escatología en homenaje a Manuel Lacunza
}

Sobre la vida de Manuel Lacunza y Díaz, s.j., podemos recordar brevemente que nació en Santiago de Chile el 19 de julio de 1731. Fueron sus padres D. Carlos Lacunza Iziaurre, natural de Artajona, Navarra, y Da Josefa Díaz Durán, hija del matrimonio chileno formado por D. Manuel Díaz Montero y Da Rafaela Durán. En agosto de 1741 ingresó al colegio San Francisco Javier, perteneciente a los jesuitas. Rinde con éxito sus estudios de filosofía. Egresa del colegio en 1747, y en septiembre del mismo año ingresa a la Compañía de Jesús. Las matemáticas y la contemplación de los astros le apasionaban. Por su cuenta estudia nociones de geometría y astronomía. En 1755, a los veinticuatro años de edad, se ordena de sacerdote. Enseña gramática y trabaja en algunas misiones cerca de Santiago. En 1767, junto con todos sus compañeros jesuitas, es expulsado de Chile e inicia un largo exilio del cual no retornaría. En España, Carlos III suprime la Compañía ese mismo año. Junto con otros jesuitas chilenos, Lacunza fijó su residencia en Imola. Al poco tiempo, el 16 de agosto de 1773, se daba a conocer el Breve de extinción de la Compañía firmado por el papa Clemente XIV. Lacunza termina de escribir su obra La Venida del Mesías en Gloria y Majestad, en 1790. En la mañana del 18 de junio de 1801 hallaron su cadáver en una poza de agua poco profunda al borde del río Santerno, en los alrededores de la ciudad de Imola. Se estima que el día anterior, el 17 de junio, en su habitual paseo vespertino, sufrió una casual caída en el río y perdió la vida. Fue enterrado en la iglesia de Pío Sufragio. Estaba por cumplir los setenta años.

El primer tomo de su libro lo terminó en 1784. Desde esa fecha se confeccionaron varios manuscritos, de los que se conservan cuatro completos en archivos y bibliotecas chilenas, y otros dos compendiados. Los estudios filológicos y bibliográficos sobre la obra de Lacunza describen al menos ocho ediciones aparecidas entre 1811 y 1826: tres en España, dos en Inglaterra, dos en México y una en Francia. Respecto a las traducciones, se puede afirmar que existen al latín, al italiano, al inglés y al francés. Además, se han hecho cuatro extractos en lengua española, uno 
en francés y otro en inglés. Finalmente, se conocen dos ediciones resumidas con análisis en español y una en francés. La obra fue colocada en el Índice en 1824 y sobre la doctrina misma el Santo Oficio se pronunció el 21 de julio de 1944: "El sistema del milenarismo mitigado no puede enseñarse con seguridad" (DS, 3839).

Para recordar la figura y la obra del jesuita chileno, y en el marco de la conmemoración del bicentenario de su muerte, la Facultad de Teología y la Facultad de Historia, Geografía y Ciencia Política de la Pontificia Universidad Católica de Chile, junto con la Universidad Alberto Hurtado y la Universidad Andrés Bello, organizaron, en septiembre del año 2002, un seminario internacional que contó con la participación de académicos y expertos de Italia, España y Chile. El presente número de la revista Teología y Vida recoge las ponencias presentadas. Roberto Rusconi, uno de los más destacados medievalistas italianos, expone sobre milenarismo y mesianismo en la historia; Adriano Prosperi, estudioso de la historia religiosa de los siglos XVI y XVII y experto en historia del Santo Oficio, presenta una ponencia sobre América y el Apocalipsis en el siglo XVI; Josep Ignaci Saranyana, historiador español, se refiere a la obra de Joaquín de Fiore y su proyección en el mundo tardomedieval; el Rabino Roberto Feldmann analiza el milenarismo desde la perspectiva judía; Claudio Pierantoni desarrolla el tema en el periodo patrístico, y el profesor Fredy Parra estudia la comprensión de la temporalidad que se encuentra en la obra de Manuel Lacunza.

Fredy Parra

Profesor Facultad de Teología

P. Universidad Católica 